\title{
POST-TRAUMATIC ADRENAL APOPLEXY
}

\author{
BY \\ SIMON SEVITT \\ From the Pathology Department, Birmingham Accident Hospital and M.R.C. Industrial Injuries \\ and Burns Research Unit
}

(RECEIVED FOR PUBLICATION FEBRUARY 25, 1955)

The first description of haemorrhage into the adrenal glands is attributed to Griselius, of Vienna, in 1670 (Doran, 1907). In the nineteenth century cases, mostly of obscure aetiology, were described by Rayer (1837), Dickinson (1863), Mattei (1883), Carrington (1885), Churton (1886), and others, and Arnaud (1900) collected and reviewed 79 cases. Since then reports of patients with gross adrenal haemorrhage have been not infrequent, and the two clinico-pathological pictures of adrenal haemorrhage in the newborn and that associated with fulminating meningococcal septicaemia, now known as the Waterhouse-Friderichsen syndrome, have been separated. This has left many cases associated with diverse conditions. In some the haemorrhage has been spontaneous and unassociated with other disorders (e.g., Pearl and Brunn, 1928 ; Barsoum, 1936 ; Thorstad, 1942 ; Falconer, 1953). Occasionally extensive adrenal haemorrhage complicates severe burns (Dudgeon, 1904 ; Weiskotten, 1919 ; Harris, 1929 ; Snelling and Erb, 1935); sometimes it is associated with pregnancy or the puerperium (Hall and Hemken, 1936; Keele and Keele, 1942 ; Hurter, 1946 ; Dewhurst, 1951 ; Crawford, 1951); occasionally the condition complicates ulcerative colitis (Dr. P. N. Coleman, 1954, personal communication ; Wilson and Roth, 1953), agranulocytosis (Seligman, 1932), leukaemia (Lauckner and Hebbert, 1947), pneumonia, septicaemia, or cellulitis (Lusk and Brumbaugh, 1919 ; Seligman, 1932 ; Hall and Hemken, 1936). In other reports chronic visceral disease has been found (Simmonds, 1902), such as chronic pancreatitis (Lavenson, 1908), hydatid hepatic cyst (Godfrey, 1947), tuberculous pyelonephritis (Thorstad, 1942), and secondary carcinoma (Seligman, 1932), and occasionally fatal adrenal haemorrhage is said to complicate an abdominal operation (Taylor, 1930).

The first reports of cases following injury were those of Canton (1863) and Mattei (1883), but haemorrhage into the adrenals of guinea-pigs was observed by Brown-Séquard in 1852 after section of the spinal cord. In his review Arnaud con- cluded that only three out of 79 cases were due to trauma, and Lavenson (1908) could find only those reported by Canton and Mattei. In Pearl and Brunn's (1928) review there were no new cases attributed to injury, but since then at least seven cases have been reported, three by Seligman (1932) and one each by Chandler (1934), by Snelling and Erb (1935), by Thorstad (1942), and by Antonini (quoted by Thorstad).

The purpose of this paper is to describe 14 cases of unilateral or bilateral haemorrhage of the adrenal glands following severe injuries, to discuss the pathogenesis of this condition, and to attempt an assessment of its clinical and pathological significance.

\section{The Patients}

From 1948 to 1954 , 50 necropsies were performed in the Birmingham Accident Hospital on patients who died after severe injuries to the chest or abdomen, and in 13 of these one or both adrenals were considerably haemorrhagic $(26 \%)$. Another patient (Case 11) with severe lower limb injuries and only slight abdominal trauma also had a unilateral adrenal apoplexy, and these 14 patients form the basis of the present study.* The haemorrhage was bilateral in three subjects and unilateral in the other 11 , nine of which involved the right adrenal.

Table I lists the age, sex, survival period, type of accident, and main injuries of each patient, together with any operation performed and significant complications. Thirteen patients were males, but this preponderance is probably occupational: 12 were adults, six under 40 years of age. Three fell from a height at work and the remainder were involved in road accidents with a motor or other vehicle. One patient died eight days after injury and the remainder within five days; two of these died within 24 hours and five

\footnotetext{
*Among the 50 necropsies were two others in each of which a small central blood clot, 2-3 $\mathrm{mm}$. diameter, was found in one adrenai. These glands have also been studied, as they show the minimal lesions which may occur.
} 
TABLE I

SUMMARY OF TRAUMA IN 14 CASES

\begin{tabular}{|c|c|c|c|c|c|c|}
\hline $\begin{array}{l}\text { Case } \\
\text { No. }\end{array}$ & $\begin{array}{l}\text { Sex } \\
\text { Age }\end{array}$ & $\begin{array}{l}\text { and } \\
(\mathrm{Yr} .)\end{array}$ & $\begin{array}{c}\text { Survival } \\
\text { Period }\end{array}$ & Mode of Injury & Main Injuries and Other Findings & $\begin{array}{l}\text { Adrenal } \\
\text { Apoplexy* }\end{array}$ \\
\hline 1 & $\mathbf{M}$ & 57 & 3 days & Fall from a height & $\begin{array}{l}\text { Fractures } 2 \text { to } 7 \mathrm{R} \text {. ribs; fracture-dislocation R. pelvis. Ab- } \\
\text { dominal distension, vomiting. Uraemia (blood urea } \\
280 \mathrm{mg} . \% \text { ) }\end{array}$ & $\begin{array}{l}\text { Bilateral. } \\
\text { total. } \\
\text { partial }(1)\end{array}$ \\
\hline 2 & $\mathbf{M}$ & 39 & 2, & Run over by a lorry & $\begin{array}{l}\text { Ruptured L. diaphragm. Fractures } 7 \text { to } 11 \text { L. ribs, haemo- } \\
\text { thoraces. Fractures ilium, L. tibia, fibula, femur. Small } \\
\text { laceration liver, torn jejunum, colon deperitonealized. (Op. } \\
\text {-colostomy, etc.) }\end{array}$ & $\begin{array}{l}\text { Bilateral } \\
\text { R.-partial } \\
\text { L.-partial }\end{array}$ \\
\hline 3 & $\mathbf{M}$ & 36 & , & Pinned under a bus & $\begin{array}{l}\text { Rupture L. kidney, spleen. Cracks R. and L. liver (op. } \\
\text { splenectomy, liver packed). Low B.P. ( } 8040) \text { Uncon- } \\
\text { scious after } 18 \text { hours. Oliguria, uraemia (blood urea } \\
210 \mathrm{mg} \% \% \text {. Cerebral ring haemorrhages }+-\end{array}$ & $\begin{array}{l}\text { Bilateral } \\
\text { R.- - subtotal } \\
\text { L.-partial }\end{array}$ \\
\hline 4 & $\mathbf{M}$ & 39 & 26 hours & $\begin{array}{l}\text { Crushed between a } \\
\text { lorry and a siding }\end{array}$ & $\begin{array}{l}\text { Superficial tear L. liver (op. packed). Biliuria. Traumatic } \\
\text { asphyxia. Myocardium bruised. } \\
\text { Sudden collapse } 3 \mathrm{hr} \text {. before death }\end{array}$ & R.-partial (t) \\
\hline 5 & $\mathbf{M}$ & 21 & 1 day & $\begin{array}{l}\text { Kicked by a horse, run } \\
\text { over by cart }\end{array}$ & $\begin{array}{l}\text { Gross rupture R. liver, torn hepatic vein. Haemoperitoneum } \\
++++ \text { Rupture } L \text {. renal vein, bruised kidney. Fractures } \\
\text { R. and L. ribs, bilateral haemothorax. Fracture humerus. } \\
\text { (Op. liver packed) }\end{array}$ & R.-total \\
\hline 6 & $\mathbf{M}$ & 58 & $3 \frac{1}{2}$ days & Car accident & $\begin{array}{l}\text { Fractures } 9 \text { to } 11 \mathrm{~L} \text {. ribs, L. haemothorax, rupture pleura. } \\
\text { Multiple fractures calvarium, cerebral laceration. Medul- } \\
\text { lary-cerebellar coning. (Op. removal comminuted frac- } \\
\text { tures skull.) Sudden collapse day } 2\end{array}$ & R.-subtotal \\
\hline 7 & $\mathbf{M}$ & 78 & , & Knocked down by a car & $\begin{array}{l}\text { Fractures } 7 \mathrm{R} \text {. rib, bloody pleural effusion. Multiple fractures } \\
\text { pelvis, central dislocated } \mathrm{R} \text {. hip. Medullary-cerebellar } \\
\text { coning. (Op. cystotomy.) Collapsed twice day } 3\end{array}$ & R.-partial (l) \\
\hline 8 & $\mathbf{M}$ & 70 & $3 \frac{1}{2}$ hours & $\begin{array}{l}\text { Hit by a crane, fell from } \\
\text { a height }\end{array}$ & $\begin{array}{l}\text { Fractures R. } 1 \text { to } 10 \text { ribs, ilium, skull. Amputation both } \\
\text { hands. (Op.-amputation completed.) Post-op. sudden } \\
\text { death. Severe coronary atheroma }\end{array}$ & R.-partial ( $\left.\frac{1}{3}\right)$ \\
\hline 9 & $\mathbf{M}$ & 36 & 5 days & $\begin{array}{l}\text { Fell off scaffold } 25 \text { feet. } \\
\text { Hit chest and abdo- } \\
\text { men on way down }\end{array}$ & $\begin{array}{l}\text { Ruptured } R \text {. liver }++. \quad \text { (Op.-laparotomy.) Fractures } \\
\text { sternum, } 2 \text { to } 9 \mathrm{R} \text {. ribs. Infected haemothoraces. Early } \\
\text { peritonitis. Bronchopneumonia }\end{array}$ & $\begin{array}{l}\left.\text { R. - partial ( } \frac{1}{2}\right) \\
\text { with diffuse } \\
\text { haemorrhage }\end{array}$ \\
\hline 10 & $\mathbf{M}$ & 54 & $1 \frac{2}{3}$ & Knocked down by a car & $\begin{array}{l}\text { Bilateral multiple fractures ribs, L. haemopneumothorax, small } \\
\mathbf{R} \text {. haemothorax. Superficial tear R. liver. Fractures skull } \\
\text { and slight cerebral haemorrhage. Medullary cerebellar } \\
\text { coning. Dislocated elbow. (Op.-reduced) }\end{array}$ & R.-total \\
\hline 11 & $\mathbf{M}$ & 38 & , , & $\begin{array}{l}\text { Found lying in the road } \\
\text { besite a truck }\end{array}$ & $\begin{array}{l}\text { Bruising round duodenum, hepatic colon. Severe laceration } \\
\text { and fracture } \mathrm{L} \text {. thigh; perineal, anal laceration. Com- } \\
\text { pound fracture } \mathrm{R} \text {. tibia, fibula. Myohaemoglobinuria. (Op. } \\
\mathrm{L} \text {. thigh amputation, transverse colostomy.) Small myo- } \\
\text { cardial rupture. (Myocarditis and fragmentation) }\end{array}$ & R.-total \\
\hline 12 & $\mathbf{F}$ & 55 & 21 hours & Knocked down by a car & $\begin{array}{l}\text { Rupture spleen, L. kidney. (Op. nephrectomy.) Haemoperi- } \\
\text { toneum }++ \text {. Fractures } 3 \text { to } 10 \mathrm{~L} \text {. ribs, small haemo- } \\
\text { thorax. Fracture humerus }\end{array}$ & L.-total \\
\hline 13 & $\mathbf{M}$ & 5 & $1 \frac{1}{2}$ days & Run over by a bus & $\begin{array}{l}\text { Small L. haemothorax, torn pleura (ribs intact). Massive L. } \\
\text { atelectasis. Capsule tear spleen. L. kidney bruised. Frac- } \\
\text { ture pelvis. Severe laceration L. thigh, perineum. (Op. } \\
\text { repair of laceration) }\end{array}$ & L._partial ( $\left(\frac{1}{3}\right)$ \\
\hline 14 & & 72 & , & $\begin{array}{l}\text { Knocked down by a } \\
\text { cyclist }\end{array}$ & $\begin{array}{l}\text { Multiple fractures R. ribs, cracks R. liver, ruptured right } \\
\text { kidney. (Op. - liver suture.) Post-op. paralytic ileus } \\
\text { (recovered). Bronchopneumonia. Infarct L. kidney }\end{array}$ & R.-partial $\left(\begin{array}{l}1 \\
6\end{array}\right)$ \\
\hline
\end{tabular}

* In total and partial apoplexies the whole or part of the medulla respectively is occupied by haemorrhage (see text). The fraction indicate the medullary area involved.

on the second day. The mode and nature of many of the injuries indicated that the abdomen or thorax had been crushed.

Thoracic and Abdominal Injuries. - Closed abdominal or thoracic injuries were found in all 14 subjects, in 13 of whom the injuries were severe. $\mathrm{Rib}$ fractures on one or both sides were found in 10 and were usually associated with a unilateral or bilateral haemothorax; in two patients a pneumothorax was also present. One patient ha他 a ruptured diaphragm, in another the heart was? bruised and a haemopericardium later proved fata丣 (Case 4). In eight subjects the abdominal viscera were injured, seven of whom also suffered a ches棸 injury: the liver was ruptured or cracked in sever? (the main hepatic vein was torn in the one who received 52 pints of blood), the spleens of three were ruptured or torn, and in one patient the 
bowel was also torn and partly deperitonealized. In five subjects one or other kidney was ruptured or bruised. In one patient (Case 11) abdominal injury was confined to bruising around the duodenum and hepatic colon.

Other Injuries.-These were often severe and multiple. Significant pelvic injuries were found in five patients who also received injuries to the chest or abdomen. The pelvis was badly fractured in three patients, in two of whom it was the major injury (Cases 1 and 7), but the pelvic viscera were intact.

Three subjects had fractured skulls and cerebral laceration, and haemorrhage was the major injury in Case 6.

Other injuries included fractures of the long bones (Cases 2, 5, 11), guillotine amputation of the hands (Case 8), and severe lacerations of the perineum, thigh, etc. (Cases 11 and 13). The main injuries of Case 11 were to the perineum and lower limbs.

\section{The Adrenals}

Before describing the adrenals of the present series, two anatomical types of adrenal haemorrhage must be distinguished. In the first a blood clot occupies part or the whole of the medulla and the cortex is stretched around it. The gland is enlarged and distorted in its transverse axes and may be $2 \mathrm{~cm}$. or more thick (Fig. 1). This kind,

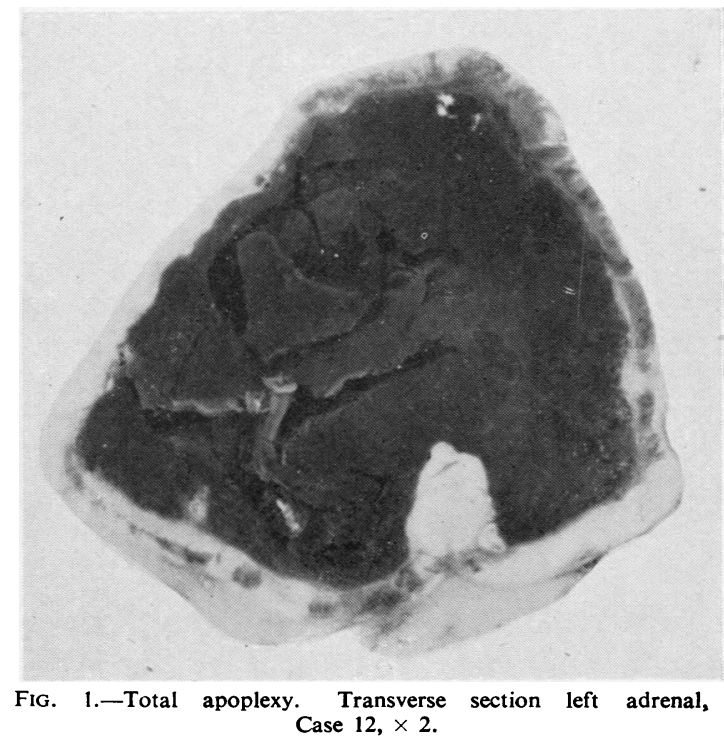

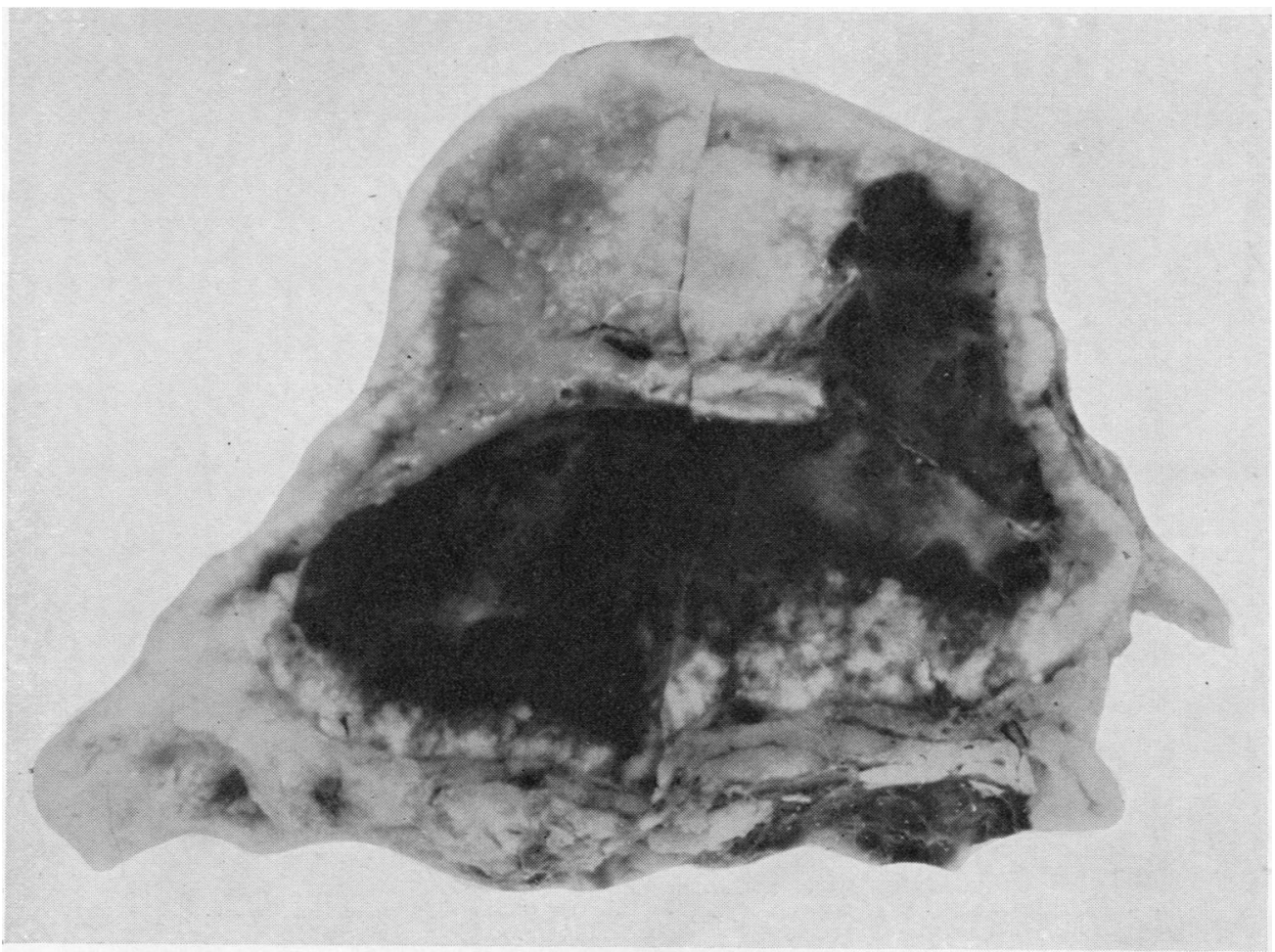

Fig. 2.-Subtotal apoplexy. Longitudinal section right adrenal, Case $3, \times 2$. 
with which the present account is concerned, will be referred to as the centrally haemorrhagic or apoplectic gland. In the second type multiple focal haemorrhages, which may coalesce, occur in the medulla and cortex, but the gland retains its normal shape. This kind was not found in the present series but has been described elsewhere (Sevitt, 1955b).

In the present series in every gland the essential lesion was a central, firm, clotted haemorrhage, usually thickest in the centre, occupying a part or the whole of the medulla (Figs. 1 to 3). The clot, which distended the gland antero-posteriorly, was surrounded by the narrow, sometimes thinned and stretched cortex, which it frequently invaded and sometimes ruptured. In one patient the clot was thickest eccentrically (Case 8), but otherwise the thickest part of the haemorrhage was in the middle.
Tiny focal haemorrhages were also visible in parts of the cortex. The central haemorrhage varied in size. Sometimes it occupied a quarter or less of the medulla. In these partial apoplexies the un- $\underline{\underline{0}}$ affected part of the gland retained its normal shape $\frac{\bar{s}}{\frac{\sigma}{\sigma}}$ (Fig. 3). In other adrenals the central clot occu- $\mathbb{\mathbb { Q }}$ pied the whole of the medulla: such apoplexies of were total (Fig. 1). Transversely sectioned through os the thickest part of the haemorrhage, the blood 0 clots varied from 7 to $15 \mathrm{~mm}$. in diameter in the $\overrightarrow{\vec{\omega}}$ partially apoplectic glands and from 20 to $25 \mathrm{~mm}$. . in those totally apoplectic.

In the bilaterally affected glands the right apoplexy was total in Case 1 , subtotal in Case $3 \dot{\omega}$ (three-quarters of the medulla was filled with clot), $\vec{\infty}$ and partial in Case 2, in which about half the $\mathrm{G}$ medulla was occupied. Within the left glands the clots were smaller, involving no more than a

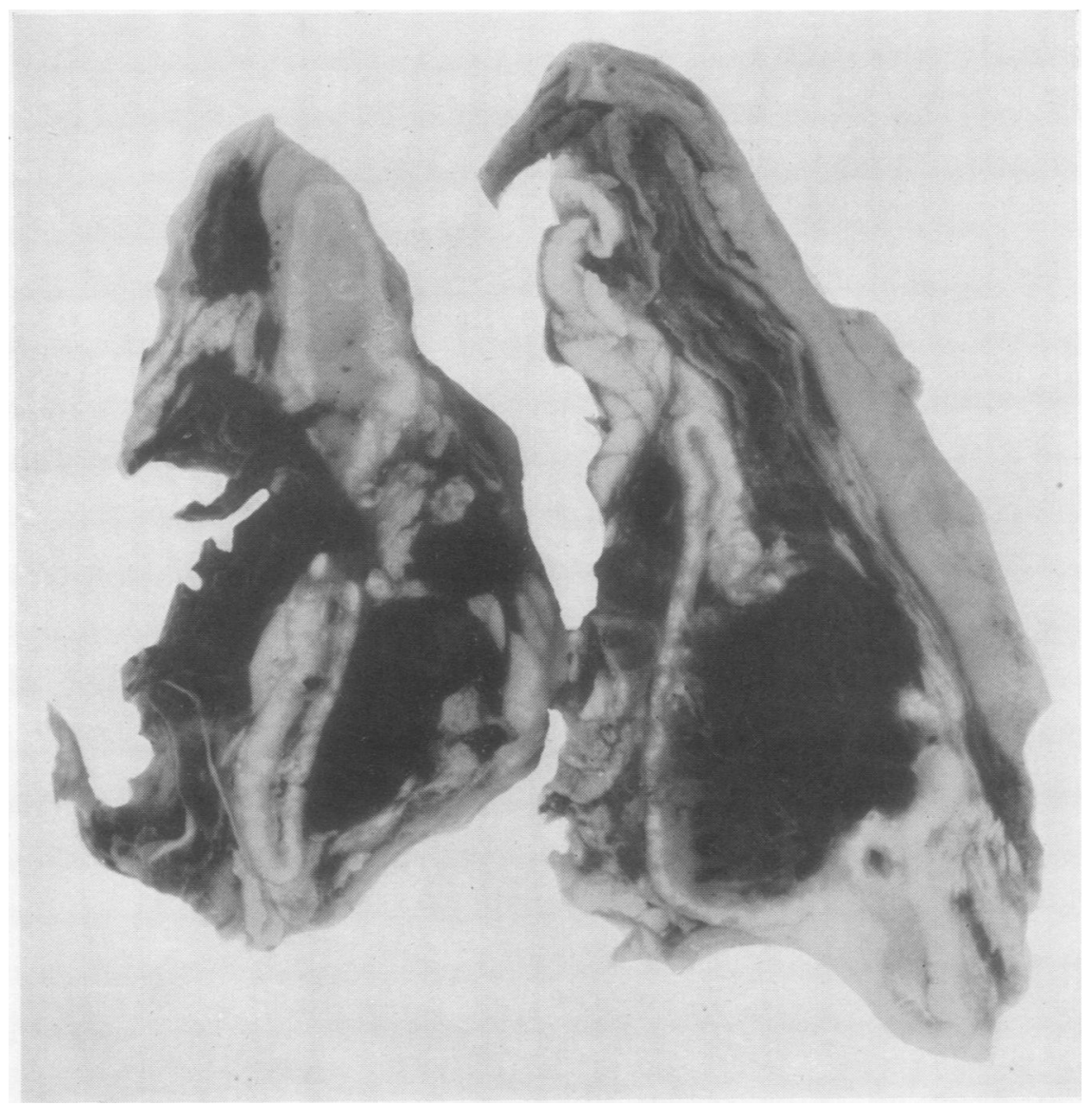

FIG. 3.-Partial apoplexy. Transverse sections of two parts of the right adrenal of Case 6 . The central medullary haemo rrhage has ruptured the cortex and has produced peri-adrenal haemorrhage, $\times 2$. 
quarter of the medulla. Four of the unilaterally affected adrenals were totally apoplectic (Cases 5, 10,11 , and 12), one subtotally (Case 6), and the remaining six were partially affected. In one of these (Case 9) the clot had ruptured through the cortex and a diffuse haemorrhage was present throughout most of the organ.

Periadrenal Haemorrhage and Rupture of the Cortex.-Haemorrhage or bruising of the periadrenal tissues of 10 glands was visible through the posterior peritoneum. This haemorrhage was never gross: it was always less than a centimetre thick and in four cases was merely a bruising of the periadrenal fat. In four patients it was associated with a local rupture of the cortex (Fig. 3) through which the central and external haemorrhages communicated (Cases 3 (right gland), 4, 6, and 8). Since similar haemorrhage was also found outside the intact glands and sometimes in other injured patients, it can arise independently of intra-adrenal haemorrhage.

Histology.-The right and left glands were fixed in $10 \%$ formol saline and paraffin sections were cut at $5 \mu$. These were stained with haematoxylin and eosin, by Perl's method for iron, by Weigert's fibrin method, and Verhoef's and Van Gieson's techniques for elastica, smooth muscle, and connective tissue of blood vessels.

The central blood clots which had completely or almost completely destroyed the medullary tissue were formed of densely packed erythrocytes lying within an irregular and often poor fibrin network. The haemorrhage was recent: red cell dehaemoglobinization, haemosiderin pigment and organization of the periphery of the clot were absent. In some glands a dense, narrow layer of leucocytes near the edge of part of the clot was externally layered by further haemorrhage, suggesting that the bleeding may have occurred in two stages.

The central haemorrhage irregularly invaded the cortex, in some places as far as the capsule, in others to the zona reticularis or fasciculata. The boundary of the haemorrhagic area was often infiltrated by polymorphonuclear leucocytes which sometimes invaded the reticularis where the haemorrhage was confined to the medulla.

Discrete, often multiple foci of cortical haemorrhage were also seen.

Cortical necrosis was either associated with haemorrhage or was free of haemorrhage. Haemorrhagic necrosis was more extensive in some (e.g., Cases 6, 10, and 12) than in others (e.g., Cases $7,8,14)$. The necrotic areas were usually coextensive with the haemorrhage, sometimes extended beyond it, and some discrete foci were found histologically remote from the central clot.

Foci of necrosis without haemorrhage were also present in every gland. In some places the zona reticularis and inner fasciculata bordering the central clot were necrotic; often irregular focal zones of necrosis involved the fasciculata or less commonly the glomerulosa. The epithelial cells were necrotic, but the cortical architecture was often intact and the sinusoids sometimes congested. In the affected parts the epithelial cell nuclei had usually disappeared, but occasionally they were dense and pyknotic: the cytoplasm was either uniformly eosinophilic or had been partially disintegrated by multiple vacuoles. Many necrotic areas were loosely infiltrated by polymorphonuclear leucocytes which were denser at the periphery. In some an eosinophilic, albuminous exudate was present, particularly in zones bordering the central haemorrhage, and in one gland the exudate was partly fibrinous (Case 1, right gland). Some necrotic areas were bordered by haemorrhage, others by normal cortex. The necrosis was probably the result of ischaemia from local pressure or near-by haemorrhage. However, in every gland much of the cortex was normal, in some the major part.

\section{Pathogenesis of Post-traumatic Adrenal Apoplexy}

Most of the bleeding comes not from the solid cortex but from the looser medulla and juxtamedullary cortex. It will be shown that rupture of small vessels, mainly sinusoids and venules, is probably brought about by a temporary compression of the gland.

The Vessels. - The adrenal has a rich blood supply from three or more arteries which pass through the capsule and break up into a sinusoidal network in the cortex. Drainage is effected through a single emissary vein which passes through the medulla, where it is joined by tributary vessels which drain the medulla and the juxtamedullary cortex.

Medium-sized and small venules were always found at the periphery of the clot, usually in the juxta-medullary cortex, and occasionally within the clot. In 12 of the 17 glands small tears, fissures, or ruptures were present in the walls of venules possessing a smooth muscle coat and in endothelial-lined channels. Similar ruptures were seen in the two glands containing the small central clots referred to in the footnote on page 185 . Either part or the whole thickness of the wall was 
torn and a trickle of red cells could often be seen in the gap. The venous walls were often oedematous, occasionally necrotic, and sometimes infiltrated by polymorphonuclear leucocytes.

Venous thrombosis has been stressed by various writers as the important factor producing adrenal haemorrhage (e.g., Hall and Hemken, 1936 ; Keele and Keele, 1942). In the present series venous thrombi were found in only one gland (right gland, Case 2). Here a few medium-sized veins contained hyaline thrombi, but torn venules were also present. The venous thrombosis probably developed after the haemorrhage had occurred. In two glands hyaline thrombosis of some cortical sinusoids was present which must also have been post-haemorrhagic. The arteries and arterioles were intact and never thrombosed.

Mechanism of the Apoplexy.-Deeply hidden behind the abdominal cavity and protected by the liver and other organs in front and by the spinal column behind, the small adrenals are considerably protected from the effects of violence. For externally applied forces to act on an adrenal they must pass through and act upon the surrounding structures and organs. These tissues are likely to be injured if the adrenal becomes haemorrhagic. Therefore if the apoplexy is due to an anteroposterior crushing injury the haemorrhagic adrenal and injured viscera would be found on the same side. An alternative possibility is that haemorrhage is the result of an acute rise of intra-adrenal venous pressure resulting from sudden and severe compression of the inferior vena cava during the crushing injury.

Consider Case 12, a woman in whom a left adrenal apoplexy was found. She was knocked down and probably run over by a car; the spleen and left kidney were ruptured and the left thoracic cage fractured. Both the adrenal haemorrhage and the main thoraco-abdominal injuries were on the left side in this patient and in Case 13. Of the nine patients with right-sided apoplexy, eight had thoraco-abdominal injuries and in six major ipsilateral injuries were present (Cases 5, 7, 8, 9, 10, and 14). For example, in Case 14, the right ribs were fractured, the right side of the liver was cracked, the right kidney was torn, and the right adrenal was haemorrhagic. In Case 4 the bruising of the heart was probably due to crushing of the chest.

In one patient (Case 6) there was an apparent contradiction between the left-sided chest injury and the right-sided adrenal apoplexy. His apoplexy may have been the result of oblique forces transmitted to the right side of the liver, which might then have crushed the adrenal against the vertebral column. Oblique forces might also explain the apoplexy of Case 11, in which the evidence of thoraco-abdominal trauma was confined to bruising around the duodenum and hepatic colon.

Of those with both glands haemorrhagic, Case 1 fell from a height and had severe right-sided injuries, Case 2 was run over by a lorry and extensive crush injuries of the chest and abdomen were present, and in Case 3, a man who was pinned under a bus, the upper abdomen was crushed and injured.

Therefore the trauma in most patients corresponded with the side of the adrenal apoplexy and crushing injuries could be implicated. The conclusions cannot be escaped that post-traumatic adrenal haemorrhage is the result of direct violence.

Blood Transfusion.-Incompatible transfusion has been incriminated in some cases of adrenal haemorrhage (Snelling and Erb, 1935; Hurter, 1946 ; Crawford, 1951). On admission the patients were shocked and were urgently transfused. In four subjects one to four bottles of Group $\mathbf{O}$ Rhesus-negative (D-negative) blood were given first and were followed by blood of the homologous ABO and Rhesus (D) type. The remainder received only homologous blood after rapid ABO grouping and Rhesus typing, the results of which were confirmed by a slower method. Crossmatching of the first bottles of blood with the patient's serum was not possible before transfusion but was always performed later. All the crossmatches were carried out in both saline and albumin suspension at $37^{\circ} \mathrm{C}$. and no incompatibility was detected.

Four of the patients received two, three, or four bottles of blood; six were given 10 to 12 음 bottles and the remainder $6,16,21$, and 52 bottles $D$ respectively. There was no clinical or laboratory evidence of adverse reaction. The haemoglobin- $N$ uria found in Case 11 was due to myohaemoglobin.

Significance of Adrenal Apoplexy after Trauma 엉

All the patients were severely injured and only in Cases 4 and 8 was death sudden and unexpected. 0 Necropsies revealed a haemopericardium in the $\frac{}{\Phi}$ former and severe coronary atheroma in the latter. ? The post-mortem findings in Cases 5, 6, and 97 indicated that the injuries were too severe to expect $\stackrel{\circ}{\circ}$ survival, and that the death of Case 12 was due to $\stackrel{\square}{\Omega}$ haemorrhage from a ruptured spleen. Both Cases $\mathbb{\mathbb { Q }}$ 7 and 14 were over 70 years of age. In Cases 10, 11 , and 13 adrenal haemorrhage was judged to 
have a possible but doubtful clinical significance, and in the remaining three it may have contributed to the deaths of the patients, since the lesions were bilateral (Cases 1, 2, 3). However, the fatal outcome of even these patients was not surprising, since not only were the injuries severe but two of them developed renal failure (Cases 1 and 3 ) and the other had had intestinal injuries (Case 2). Nevertheless the adrenal haemorrhage may have produced its own physiopathological disorder and have been responsible for the abdominal distension and vomiting in Case 1, the low blood pressure in Case 3, and the sudden collapse of Cases 6 and 7 . The possibility that the adrenal haemorrhage played a contributory role in the deaths of these and other patients cannot be excluded on clinical grounds.

\section{Histological Tests of Adrenocortical Hyperactivity}

The influence of adrenal haemorrhage on cortical activity might be assessed by two histological tests. One of these is based on the number of eosinophil leucocytes in the spleen (Sevitt, $1955 \mathrm{a}, 1955 \mathrm{~b})$ and the other upon the depletion of cortical lipoid in the hyperactive adrenal cortex.

Splenic Eosinopenia.-Elsewhere it has been shown that the normal sp'een contains many eosinophil leucocytes, that within 12 to 24 hours of injury eosinopenia occurs and is found in those who die during the next few days (Sevitt, 1955a ; Sevitt, 1955b). It was also found that splenic eosinopenia reflects blood eosinopenia, and, since the latter is due to adrenocortical hyperactivity, the former was postulated as also reflecting this activity. Splenic eosinopenia therefore may be used as post-mortem evidence of adrenocortical hyperactivity. The normal range of eosinophils in the spleen varies from 200 to 700 per 100 high power (H.P.) fields $(\times 378)$ in $5 \mu$ paraffin sections and never falls below 100 per 100 H.P. fields. Values below 100 indicate eosinopenia. In Fig. 4 the shaded area represents the limits of the expected values after severe trauma. Up to a few hours of injury the normal range of splenic eosinophils is always present: thereafter and up to 24 hours after trauma-the transition period-either normal, intermediate, or definite eosinopenic values may occur.

Paraffin blocks of spleens were available in nine of the 14 cases. Sections were cut at $5 \mu$ and were stained by carbol-chromotrope and haematoxylin (Lendrum, 1944) which coloured the eosinophil granules a bright red. The number of eosinophil leucocytes in 200 H.P. fields from two sections was counted and the results expressed per 100 H.P. fields.

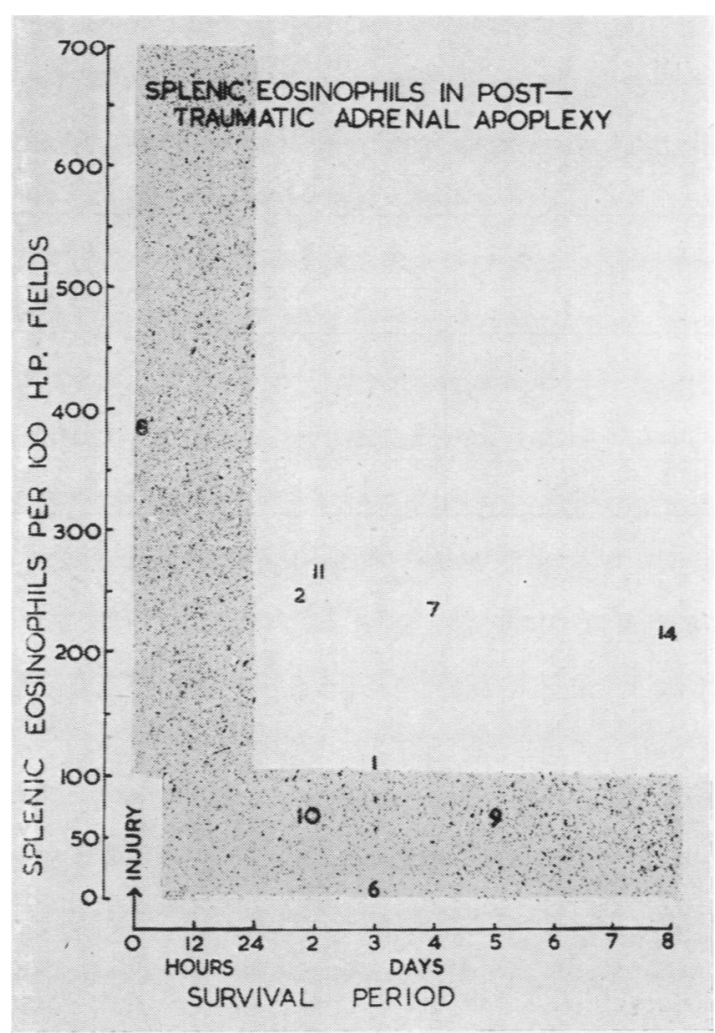

FIG. 4.

Depletion of Cortical Lipoid.-The normal resting adrenal cortex contains abundant sudanophil lipoid in all its zones. Depletion of lipoid from the human adrenal occurs after severe haemorrhage and injury (Elliott, 1914; Urechia, Manta, and Bumbacescu, 1940), and is usually associated with splenic eosinopenia (Sevitt, 1955b). Significant loss of cortical lipoid will therefore be interpreted as indicating adrenocortical hypersecretion. Conversely, if lipoid depletion, which is expected after injury, does not occur, its absence will be interpreted as indicating absence of adrenocortical hypersecretion.

In 12 of the 14 cases both adrenal glands were available for study. Frozen sections were cut at 10 to $15 \mu$, stained with Sudan IV or oil red and counterstained with haematoxylin or light green. Adrenocortical depletion of lipoid was assessed histologically as 0 , trace,,+++ , and +++ (see footnote of Table II). 
Results.-These are shown in Fig. 4 and Table II.

In Cases 6, 9, and 10 splenic eosinopenia was present with values of 3,74 , and 77 eosinophils per 100 H.P. fields. These figures indicate adrenocortical hyperactivity. This was supported by the

TABLE II

SPLENIC EOSINOPHIL CONTENT AND LOSS OF ADRENOCORTICAL LIPOID IN 10 SUBJECTS SURVIVING MORE THAN 24 HOURS

\begin{tabular}{|c|c|c|c|c|}
\hline \multirow{2}{*}{\multicolumn{2}{|c|}{ Spleen }} & \multicolumn{3}{|c|}{$\begin{array}{c}\text { Degree of Adrenocortical Lipoid } \\
\text { Depletion }\end{array}$} \\
\hline & & 0 or Trace & ++ & +++ \\
\hline $\begin{array}{l}\text { Eosinopenic }(0-100 \\
100 \mathrm{H} . \mathrm{P} \text {. fields }) \\
\text { Doubtful } \\
\text { Eosinophilic }(>200 \\
100 \text { H.P. fields })\end{array}$ & $\begin{array}{c}\text { per } \\
\ldots \\
\ldots \\
\text { per } \\
\ldots\end{array}$ & 7,14 & $\underset{2}{6,9,10}$ & 1 \\
\hline Not available & $\cdots$ & & 3,4 & \\
\hline
\end{tabular}

Numerals refer to case numbers.

- + depletion indicates $25 \%$ to $75 \%$ of cortex affected.

$+++>75 \%$.

finding of considerable $(+-)$ depletion of cortical lipoid in the intact, non-haemorrhagic glands of these three patients (also in the apoplectic glands of Cases 6 and 9).

Splenic eosinopenia was not found in Cases 2, 7,11 , or 14 . The splenic eosinophils were 242 , 235, 262, and 210 per 100 H.P. fields respectively, all of which are within the normal range. The significance of post-traumatic splenic eosinophilia is less certain than that of splenic eosinopenia, since the former is a normal phenomenon. Splenic eosinophilia also occurs in Addison's disease (Sevitt, 1955b), but nevertheless it cannot be used in any particular case as evidence of adrenocortical failure. However, it may be used in a special group of cases such as the present one. The finding of eosinophilic values in the spleens of four out of eight patients (excluding Case 8) may be significant, since they died at a time when splenic eosinopenia would have been expected. In these patients adrenocortical activity may have been absent. In two patients, Cases 7 and 14, there was little or no depletion of cortical lipoid in either the haemorrhagic or intact glands, suggesting that there had not been any cortical hypersecretion. In these patients the combined evidence of splenic eosinophilia with lack of lipoid depletion indicated that adrenocortical failure may have occurred. This finding is unexpected not only because the adrenal apoplexies were unilateral but also because the central blood clots involved relatively small areas of the medulla (Table I). Inhibition of cortical hyperactivity, reflex or otherwise, of both intact and haemorrhagic glands must have occurred, since the absence of hyperactivity of both glands cannot be due to the direct effect of $\underset{?}{\vec{P}}$ haemorrhage.

In Case 11, however, there was great loss $\frac{C}{0}$ $(+++)$ of cortical lipoid from the intact adrenal (although the loss from the haemorrhagic gland was considerably less (trace or + ). A considerable lipoid loss was also found in the lesser haemorrhagic gland of Case 2 . In both these patients there is an apparent paradox between the splenic eosinophilia and considerable adrenocortical loss of lipoid. In the absence of other evidence the latter would appear to be the most direct evidence of hyperactivity and therefore these glands may be considered to have been in a hyperactive state at the time of death.

In Cases 1 and 3 , which were bilaterally apoplectic. cortical lipoid loss was also considerable $(++)$ in the lesser of the two haemorrhagic adrenals and indicated hyperactivity of the glands. In the former a borderline value of 104 splenic eosinophils per 100 H.P. fields was found. The considerable depletion of lipoid in the intact gland in Case 4 may also be considered as evidence of adrenocortical hyperactivity (spleen section not available).

In Case 8 a normal value of 388 eosinophils per 100 H.P. fields was found in the spleen and cortical lipoid depletion of both glands was slight. No conclusion can be reached as to the significance of these findings, since the patient died three and a half hours after injury, which was not sufficient time either for splenic eosinopenia or lipoid depletion to develop. Case 12 also died within 24 hours of injury and showed only slight evidence of $\dot{0}$ cortico-lipoid depletion (spleen section not available). Neither of these cases is included in Table II.

Therefore evidence of adrenocortical hyper- $O$ secretion based on depletion of cortical lipoid was found in eight out of 12 patients, in three or four of whom there was also splenic eosinopenic evidence of hyperactivity. In two patients both 0 the adrenal lipoid and splenic eosinophil tests $N$ indicated absence of activity of both the normal $\underset{\mathrm{N}}{\mathrm{N}}$ and apoplectic glands and suggested that adrenocortical failure due to inhibition of the glands had occurred.

\section{Discussion}

Although few cases have been previously 0 described, central haemorrhage into one, or less commonly both adrenals, is not an uncommon finding in patients who die after severe injury to $\mathbb{D}$ the chest or abdomen, as it was found in 13 out of 50 necropsied patients. It was also present in 
another severely injured patient with relatively minor abdominal trauma. It is likely that adrenal apoplexy also occurs in some of those who survive similar injuries, but at present those who are affected are not recognized and neither the incidence nor the clinical significance of the haemorrhage is known. Their recognition may be important, since any morbidity or fatality due to adrenal haemorrhage might be lessened by the administration of cortisone or other drugs.

The mechanism of the haemorrhage and its central location within the gland are probably dependent on the anatomical relationships and histological structure of the organ and the peculiarities of its blood supply. One theory, which is consistent with the data, depends on the following considerations. Parts of both glands lie in front of the spinal column against which they could be compressed when the upper abdomen or lower thorax is severely crushed. The right adrenal is more likely to be damaged than the left because much of its anterior surface is closely opposed to the liver. This could largely explain why nine of the 11 unilateral apoplexies involved the right gland. Damage to vessels occurs more readily within the spongy medulla and loosely textured zona reticularis than within the solid cortex. Rupture of the centrally situated venules and sinusoids occurs and a central haemorrhage develops which distends the peripheral cortex. Thus the typical result of injury to the adrenal is a central haemorrhage just as the classical result of trauma to the spleen or liver is a rupture. On the other hand, the central haemorrhage might follow an acute rise of intra-adrenal venous pressure resulting from sudden and severe compression of the inferior vena cava during the compression of the abdomen. The right adrenal would also be affected more often than the left because the right adrenal vein drains directly into the vena cava whilst the left vein first joins the renal vein.

Among Snelling and Erb's cases of adrenal haemorrhage, one followed a head injury, and cerebral injury was also found in two of Seligman's cases and in Cases 6, 8, and 10 . The question arises whether cerebral injury, nervous stimulation, or shock can produce adrenal haemorrhage, as this might also explain the contra!ateral adrenal haemorrhages in Case 6 and in Seligman's Case 1, and also the apoplexy in Case 11, in which severe thoraco-abdominal injury was absent. On the other hand, the writer has never seen adrenal apoplexy in a not inconsiderable necropsy experience of cerebral, spinal cord, and other severe injuries, so that adrenal haemorrhage from nervous irritation or shock must be a rare condition if it occurs at all. It is therefore suggested that these apparent paradoxes are due to unsuspected mechanical stresses acting on the adrenal which reach it through a complex thoracic or abdominal pathway.

Any clinico-pathological significance attached to adrenal apoplexy is probably due to interference with cortical rather than medullary function, since only the cortex is essential to life. Cortical activity may be affected in two ways. First, parts of it are destroyed by haemorrhage or otherwise rendered necrotic, but since much remains histologically viable death of tissue probably plays a minor part in reducing cortical activity. Secondly, the pressure of the central haemorrhage could interfere with the venous drainage of the gland and abolish or reduce the venous blood flow, particularly when the clot fills the whole medullary space. Formation of hormones may cease, or, if the capillary blood flow persists, may continue for a time and depletion of cortical lipoid may occur even though the secretions never reach the inferior vena cava. This may have occurred, for example, in the totally apoplectic gland of Case 1 in which considerable depletion of cortical lipoid was found. In partially apoplectic glands the secretion from the hyperactive cortex will reach the general circulation, since drainage of the venous tributaries in the unaffected part of the medulla will continue unless the main vein is compressed near its place of exit.

Clinical assessment of the significance of the apoplexies was rendered difficult because all the patients were severely injured, and death was usually not surprising. However, the possibility that certain symptoms were due to the haemorrhagic adrenals and that acute adrenocortical failure played a contributory role in the death of some patients could not be excluded.

Two histological tests for adrenocortical hyperactivity, one based on eosinopenia of the spleen and the other upon the depletion of lipoid in the cortex, were of some value. Evidence of adrenocortical hyperactivity based on loss of cortical lipoid was found in eight out of 12 patients, in three (or four) of whom there was also splenic eosinopenia. Certainly in these three or four patients physiological failure of cortical activity had not occurred. On the other hand, the finding of splenic eosinophilia in four out of eight patients who died at a time after injury when eosinopenia would have been expected suggested that adrenocortical hyperactivity may have been 
absent and that physiological failure may have occurred. In two cases the absence of scanty loss of cortical lipoid from both the intact and apoplectic glands supported this. As only one gland was haemorrhagic, activity of the cortex of the intact gland must have been inhibited. In the other two patients the considerable loss of cortical lipoid was local evidence of cortical hypersecretion, but in the bilaterally haemorrhagic subject the endocrine secreted may never have reached the systemic circulation because of possible pressure on the central adrenal veins. This cannot explain the association of splenic eosinophilia with severe loss of lipoid in the patient with unilateral adrenal haemorrhage, but a similar association occasionally occurs in patients with intact adrenals (Sevitt, 1955b).

\section{Summary}

Central apoplexy of one or both adrenal glands was found in 13 out of 50 patients who died after severe closed injuries to chest or abdomen $(26 \%)$ and in another severely injured patient showing slight evidence of abdominal injury. Evidence is advanced that crushing of the glands tears the medullary venules and is responsible for the central haemorrhage. This stretches the cortex, often invades it, and sometimes ruptures it.

The significance of the apoplexies was estimated by two histological tests of adrenocortical hyperactivity, one based on the eosinophil content of the spleen and the other on depletion of adrenocortical lipoid, particularly in the non-haemorrhagic glands. Both were in agreement that cortical hyperactivity had been present in at least three or four patients. Evidence of hyperactivity based on cortical lipoid loss alone was found in eight out of 12 cases examined. The results of both tests suggested that adrenocortical failure due to glandular inhibition had occurred in two patients with unilateral apoplexy.

\section{Addendum}

During the first few months of 1955 , necropsies were performed on 10 patients with closed thoracic, abdominal, or pelvic injuries and adrenal apoplexy was found in three of them. This makes a total of 16 out of 60 cases (approximately 27\%). The first subject (male, 23 years), who died two days after a road accident, sustained multiple right rib fractures and a lacerated lung. He had an incomplete right adrenal apoplexy. Extreme eosinopenia of the spleen and partial depletion of lipoid from the left adrenal cortex indicated adrenocortical hyperactivity. In the second patient (male, 7 years) bilateral adrenal apoplexy appeared to have precipitated or accelerated his death. $\mathrm{He}^{\stackrel{\text { }}{*}}$ was knocked down by a van, susiained a compound $\overrightarrow{\vec{\rho}^{*}}$ fracture of the right tibia and fibula and a ruptured spleen which was removed. He was trans- $\frac{\bar{O}}{0}$ fused with 2 pints of blood. Next day, sudden col- $\overline{\overline{\bar{N}}}$. lapse was associated with sudden tachycardia (pulse $ه$ 160 ), respirations 40 and a fall of blood pressure to $90 / 60$. Soon he became unconscious and died four hours after his collapse and about two days $\vec{\circ}$ after injury. Necropsy revealed fractures of right $\overrightarrow{\vec{H}}$ ribs 9-12, a central haemorrhagic laceration of the right side of the liver with superficial tears of the left side, a slight bruise of the right frontal cerebral ${ }_{\infty}$ lobe, and a bilateral total adrenal apoplexy. $\omega$ Histologically there was complete haemorrhagic $\vec{\infty}$ necrosis of the medullae and cortices and the latter ${ }^{G}$ were stuffed with lipoid. Unfortunately the spleen ${ }^{\circ}$ had been discarded. The third patient (male, $78-$ years) fell down the stairs and fractured the ninth and tenth right ribs. He died 10 days later; severe coronary sclerosis, duodenal ulceration, an old $\stackrel{\text { ? }}{\rightarrow}$ pulmonary empyema, and a partial apoplexy of $\vec{\oplus}$ both adrenals (right more than the left) were present.

The writer is a part-time member of the scientific staff of the Medical Research Council.

Thanks are due to the surgeons concerned for the $\frac{}{\otimes}$ use of the clinical notes, to Mr. D. Gibb, A.I.M.L.T., $\varrho$ for the preparation of the sections, to the photo- $\overrightarrow{0}$ graphic department of the hospital, and to my secre- 3 tary, Mrs. M. Swinden.

\section{REFERENCES}

Arnaud, F. (1900). Arch. gén. Med., 9 ser, 4, 5.

Barsoum, H. (1936). Brit. med. J., 2, 972.

Canton, E. (1863). Trans. path. Soc., Lond., 14, 257.

Carrington, R. E. (1885). Ibid., 36, 454.

Chandler, L. R. (1934). Surg. Clin. N. Amer., 14, 1319.

Churton, T. (1886). Lancet, 1, 245.

Crawford, M. D. (1951). J. Path. Bact., 63, 365.

Dewhurst, C. J. (1951). Brit. med. J., 2, 22.

Dickinson (1863). Trans. path. Soc. Lond., 14, 256.

Doran, A. H. G. (1907). Proc. roy. Soc. Med., 1 (Surg. Sect.), 201. 의

Dudgeon, L. S. (1904). Amer. J. med. Sci., 127, 134.

Elliott, T. R. (1914). Quart. J. Med., 8, 47.

Falconer, C. D. (1953). Brit. J. Urol., 25, 183.

Godfrey, L. W. (1947). Brit. med. J., 1, 181.

Hall, E. M., and Hemken, L. (1936). Arch. intern. Med., 58, 448.

Harris, R. I. (1929). Brit. J. Surg., 16, 677.

Harris, R. I. (1929). $\quad$ Brit. J. Surg., 16, 677.
Hurter, L. E. (1946). Proc. roy. Soc. Med., 39, 581.

Keele, D. V., and Keele, K. D. (1942). Brit. med. J., 2, 687

Lavenson, R. S. (1908). Arch. intern. Med., 2, 62.

Lauckner, J. R., and Hebbert, F. J. (1947). Glass. med. J., 28, 366 C

Lendrum, A. C. (1944). J. Path. Bact, 56, 441.

Lusk, F. B., and Brumbaugh, A. (1919). J. Amer. med. Ass., 72, 1062 .

Mattei, R. (1883). Sperimentale, 51, 386

Pearl, F., and Brunn, H. (1928). Surg. Gynec. Obstet., 47, 393.

Rayer, P. (1837). Experience, 1, 17 (quoted by Arnaud, F.).

Seligman, B. (1932). Med. J. Rec., 135, 209.

Sevitt, S. (1955a). Jourral of Clinical Pahology, 8, 42.

(1955b). J. Path. Bac . In the press.

Simmonds, M. (1902). Virch. Arch. path. Anat., 170, 242.

Snelling, C. E., and Erb, I. H. (1935). J. Pediat., 6, 22.

Taylor, G. W. (1930). New Engl. J. Med., 202, 269.'

Thorstad, M. J. (1942). Amer. J. Surg., 55, 44.

Thorstad, M. J. (1942). Amer. J. Surg., 55, 44. 102, 143.

Weiskotten, H. G. (1919). J. Amer. med. Ass., 72, 259.

Wilson, D. A. W., and Roth, D. (1953). Ibid., 152, 230.

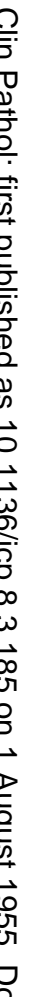

